DOI: https://doi.org/10.47405/mjssh.v6i8.922

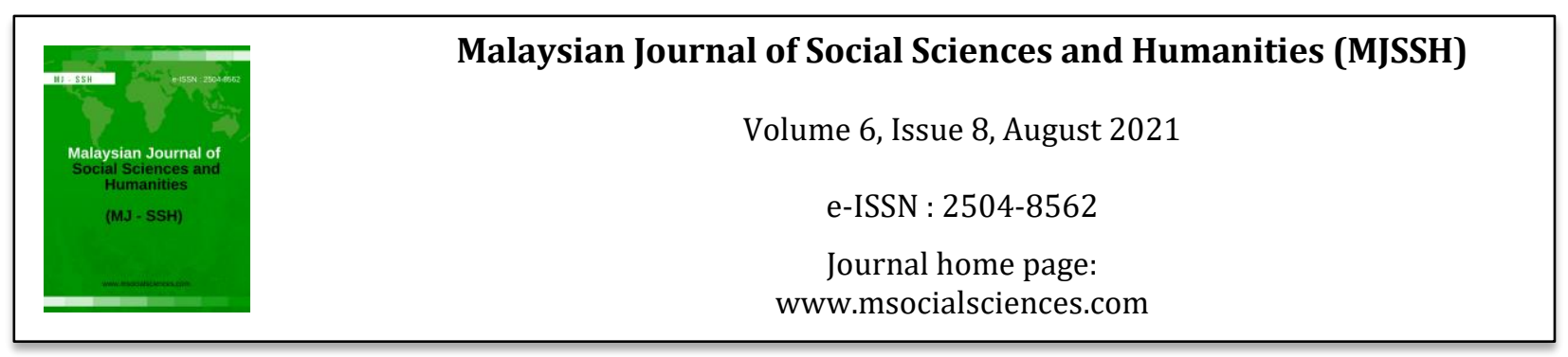

\title{
Piagam Madinah dalam Pembentukan Peradaban Multietnik Pasca Malaysia
}

\author{
Ahmad Nasir b. Mohd Yusoff ${ }^{1}$, Nik Rosniwati Ismail ${ }^{1}$, Mohd Taufik Ayup ${ }^{1}$, Mohd Shafiqul Islam ${ }^{1}$ \\ 1Jabatan Pengajian Kenegaraan dan Ketamadunan, Fakulti Ekologi Manusia, \\ Universiti Putra Malaysia (UPM)
}

Correspondence: Ahmad Nasir b. Mohd Yusoff (ahmadnasir@upm.edu.my)

\begin{abstract}
Abstrak
Islam adalah agama kebaikan, keamanan, ketenangan dan kesejahteraan kepada seluruh alam semesta. Dalam teks ucapan Tan Sri Muhyiddin Yassin sebaik memulakan tugas sebagai Perdana Menteri kelapan di Perdana Putra dan setelah mengangkat sumpah di hadapan YDPA, Al-Sultan Abdullah Ri'ayatuddin Al-Mustafa Billah Shah di Istana Negara, beliau ada menyatakan 'baik saudara orang Melayu, saudara orang Cina, saudara orang India, Sikh, Iban, Kadazan, Dusun, Murut, orang asal, atau apa jua kaum dan etnik, saya adalah Perdana Menteri saudara','kerajaan pimpinan saya akan memberi tumpuan kepada pelaksanaan Wawasan Kemakmuran Bersama 2030 yang akan melonjakkan pertumbuhan ekonomi negara dan merapatkan jurang ekonomi dalam komuniti' dan 'saya adalah Perdana Menteri untuk semua rakyat Malaysia dari Perlis hingga ke Sabah. Kata-kata ini sesuai dalam era pentadbiran Pasca Malaysia serta usaha membentuk peradaban multietnik yang sejahtera. Islam melarang manusia berlaku zalim sesama manusia termasuk haiwan. Hadis riwayat al-Imam al-Hakim, Rasulullah SAW bersabda;"Sesiapa yang dengan sewenang-wenang membunuh burung, atau haiwan lain yang lebih kecil daripadanya, maka Allah SWT akan meminta pertanggungjawaban kepadanya". Malaysia adalah negara berbilang etnik dan peradaban. Agenda penyatuan dan perpaduan kaum berbilang bangsa, agama, keturunan dan hak sama rata dijaga Perlembagaan dan Perundangan Negara, tanpa mengganggu hak-hak kaum bumiputera. Ia telah dipersetujui dalam kontrak sosial oleh kaum Melayu, Cina dan India semasa pembentukan Perlembagaan Malaysia (1957). Aspek kesepaduan etnik adalah idea kreatif dan inovatif penyatuan etnik dan kehidupan yang baik lagi makmur. Perbincangan isu ini menjadi kontemporari khususnya di era Pasca Malaysia yang mempunyai penduduk berbilang bangsa dan budaya. Komuniti Malaysia daripada golongan profesional, sokongan, bumiputera dan bukan bumiputera, bersedia menerima agenda penyatuan ini sebagai formula yang menyamaratakan semua etnik tanpa menggadaikan kontrak sosial seperti hak-hak istimewa orang Melayu, kemasukan pelajar bumiputera ke IPT, hak kerakyatan, bahasa Melayu sebagai bahasa kebangsaan dan Islam sebagai agama persekutuan. Piagam Madinah pula adalah perlembagaan bertulis dan dipersetujui bersama oleh semua golongan komuniti Islam Madinah dan komuniti Yahudi yang menjadi warganegara Madinah yang ditadbir urus oleh Rasulullah SAW. Disebut 'Sahifah al Madinah' kerana ia merupakan perlembagaan bertulis pertama di dunia serta menjadi asas pembentukan negara Islam. Terdapat 10 Bahagian dan 47 fasal. 23 fasal berkaitan peraturan antara komuniti Islam dan 24 fasal lagi berkaitan komuniti Yahudi. Menurut kajian sejarawan, terbentuknya Piagam Madinah melalui perjanjian Aqabah pertama yang dihadiri 12 penduduk Madinah. Antara intipati perjanjian seperti menjauhi syirik, membunuh anak, tidak menipu dan mentaati perintah Rasulullah SAW. Mus'ab ibn Umar diutus ke Madinah mengajar al Quran oleh Rasulullah SAW dan sambutan yang diterima amat menggalakkan oleh etnik Aus dan Khazraj. Ikatan perjanjian Aqabah Kedua juga diadakan, melibatkan 73 lelaki dan 2 wanita Madinah, dibawa oleh Mus'ab bertemu Rasulullah SAW dan berbai'ah menjaga dan mempertahankan perjuangan dakwah Rasulullah SAW. Mereka berikrar untuk tidak berpecah belah, bercakap sombong dan taat setia ketika senang atau susah. Penulisan ini melihat peranan Piagam
\end{abstract}


Madinah dalam melestarikan kehidupan, peradaban dan kesepaduan rakyat Malaysia sesuai dengan agenda pentadbiran PascaMalaysia.

Kata kunci: piagam Madinah, pembentukan peradaban, multietnik, pasca Malaysia

\title{
Medina Charter in the Formation of Post-Malaysian Multiethnic Civilization
}

\begin{abstract}
Islam is a religion of goodness, security, tranquility and prosperity to the entire universe. In the text of Tan Sri Muhyiddin Yassin's remarks as well as starting his duties as the eighth Prime Minister at Perdana Putra and after taking the oath before YDPA, Al-Sultan Abdullah Ri'ayatuddin Al-Mustafa Billah Shah at the State Palace, he stated 'Good Malay brothers, Chinese brothers, Indian brothers, Sikhs, Ibans, Kadazans, Dusuns, Muruts, people of origin, or whatever race and ethnicity, I am your Prime Minister','My government will focus on the implementation of the 2030 Common Prosperity Insight which will boost the country's economic growth and close the economic gap in the community' and 'I am the Prime Minister for all Malaysians from Perlis to Sabah. These words are appropriate in the post-Malaysian administration era as well as efforts to establish a prosperous multi-ethnic civilization. Islam forbids humans from being cruel to other humans, including animals. Hadith narrated by al-Imam al-Hakim, Rasulullah SAW said: "Whoever arbitrarily kills a bird or other animal that is smaller than it, Allah will hold him accountable". Malaysia is a country of many ethnicities and civilizations. The agenda for the unification and integration of various nations, religions, descents and equal rights is maintained by State Institutions and Legislation, without disturbing the rights of the natives. It was approved in the social contract by the Malays, Chinese and Indians during the formation of the Malaysian Institution (1957). Aspects of ethnic integration are creative and innovative ideas for ethnic unity and a good and prosperous life. Discussion of this issue has become contemporary, especially in the Post-Malaysian era which has a population of many nations and cultures. The Malaysian community, rather than professionals, supporters, bumiputera and non-bumiputeras, are willing to accept this unification agenda as a formula that equalizes all ethnicities without mortgaging social contracts such as the privileges of Malays, inclusion of bumiputera students into IPT, people's rights, Malay as the national language. and Islam as a common religion. The Medina Charter is also a written institution and is jointly approved by all groups of the Medina Islamic community and the Jewish community who are citizens of Medina which are managed by the Prophet Muhammad. It is called 'Sahifah al Madinah' because it is the first written institution in the world and is the basis for the formation of an Islamic state. There are 10 chapters and 47 chapters. 23 chapters related to regulations between the Islamic community and another 24 chapters related to the Jewish community. According to historian studies, the formation of the Medina Charter was through the first Aqabah agreement which was attended by 12 residents of Medina. Among the essence of the agreement such as avoiding shirk, killing children, not cheating and obeying the commands of the Prophet Muhammad. Mus'ab ibn Umar was sent to Medina to teach the Koran by the Prophet Muhammad and the welcome he received was very encouraging by the Aus and Khazraj ethnic groups. The Second Aqabah agreement was also held, involving 73 men and 2 women of Medina, brought by Mus'ab to meet the Prophet Muhammad and pledged allegiance to guard and defend the missionary struggle of the Prophet Muhammad They vow not to divide, speak arrogantly and be loyal when happy or sad. This writing looks at the role of the Medina Charter in preserving the life, civilization and cohesion of the Malaysian people in accordance with the Post-Malaysia administration agenda.
\end{abstract}

Keywords: Medina charter, formation of civilization, multiethnic, post Malaysia 


\section{Pengenalan}

Maqasid Syariah dijangkakan antara model urus tadbir Malaysia dan menjadi agenda pentadbiran PascaMalaysia. Cara hidup berpandukan al-Quran dan sunnah melalui konsep 'ta'awunun 'alal birri wa taqwwa' (tolong menolong dalam perkara kebaikan) perlu diperkukuhkan di peringkat pentadbiran negara, serta institusi pendidikan. Bagi memastikan gagasan pentadbiran kerajaan Malaysia ini dihayati, maka ia perlu diterapkan kepada pelajar sekolah rendah lagi hingga ke peringkat pengajian tinggi. Usaha menghidupkan pengajian al-Quran dan sunnah di masjid, surau, pejabat dan rumah dalam bentuk pengajaran, ceramah, muzakarah dan halaqah perlu dilestarikan. Syiar ini diterjemahkan dalam aktiviti-aktiviti komuniti agar semua program mendapat kebaikan. Hubungan komuniti Islam dengan bukan Islam perlu bersifat meraikan, menghormati serta tidak mencetuskan isu-isu sentimen dan permusuhan. Allah SWT tidak melarang berbuat baik kepada komuniti bukan Islam yang tidak memerangi Islam atau menghalau komuniti Islam dari tanah air. Harus berbuat baik sesama manusia tanpa mengira latar belakang etnik. Dakwah kepada bukan Islam boleh dilakukan melalui akhlak yang baik dan bijaksana.

\section{Kajian Lepas}

Menurut kajian Mohd Nazmi, Suraya dan Syamsul (2020) menyatakan antara tujuan Rasulullah SAW menggubal perlembagaan Piagam Madinah merangkumi aspek politik, agama, ekonomi, sosial, perundangan dan pertahanan termasuk kedudukan Yahudi yang juga diberi jaminan keselamatan selagi mematuhi Piagam Madinah sama sepertimana yang dilakukan Rasulullah SAW ketika mengikat persaudaraan antara suku Aus dan Khazraj yang dahulunya bermusuhan, berperang dan hasad dengki di antara mereka berubah kepada kasih dan cinta dengan izin Allah SWT. Penggubalan Piagam Madinah ini adalah berasaskan prinsip keadilan, toleransi, hormat serta kasih sayang.

Sementara itu, kajian yang dilakukan oleh Luqman (2012) menyatakan bahawa Islam menganggap etnosentrisme sebagai musuh besar, kerana pilih kasih adalah serangan terhadap transendensi Tuhan itu sendiri. Agar kedudukan Tuhan tetap tertinggi, semua makhluk harus setara. Piagam Madinah yang dibangunkan Rasulullah SAW sendiri telah menggabungkan unsur-unsur ini, menerapkan konsep kesamarataan, sehingga ummah dalam Piagam Madinah sangat jauh dari etnosentrisme.

Berdasarkan kajian-kajian terdahulu, salah satu strategi yang dilaksanakan Rasulullah SAW melalui Piagam Madinah yang disesuaikan dengan budaya dan bangsa yang berada di Madinah. Melalui Piagam Madinah, masyarakat atau etnik yang terdiri daripada etnik Bani Nadhir, Qainuqa' dan lain dapat hidup dalam suasana harmonis dengan Perlembagaan Madinah menjadi panduan peraturan dalam kehidupan yang berbilang budaya.

\section{Metod Kajian}

Kajian ini merupakan kajian kualitatif dengan menggunakan pendekatan content analysis (analisis kandungan) di mana pengkajian menggunakan sumber dari jurnal, majalah, surat khabar, buletin dan sebagainya untuk mengolah kandungan artikel (Fraenkel \& Wallen, 1993). Di dalam menggunakan kaedah analisis kandungan ini, ia perlu dimulakan dengan menyediakan latar belakang atau menjelaskan teori kajian. Ini bermakna penulis perlu mengetahui aspek yang hendak dikaji dengan memfokuskan kepada kandungan untuk dibahasakan. Ini dilakukan dengan membaca, menganalisis dan menstrukturkan kandungan yang berkaitan mengikut topik kajian literatur. Seterusnya, hubung kait antara cadangan atau topik kajian literatur dengan penyelidikan yang telah dilakukan dicari. Hubung kait juga perlu dilakukan terhadap sumber tidak rasmi seperti surat khabar, majalah dan buletin. Kemudian bahan ini diintegrasikan dengan hasil kajian iaitu kandungan yang telah dihubung kait untuk diadunkan dengan pengetahuan sendiri. Proses ini juga memerlukan analisis kritikal sebelum melakukan proses terakhir di mana laporan penuh disediakan dengan menggabungkan bahan- 
DOI: https://doi.org/10.47405/mjssh.v6i8.922

bahan berhubung Piagam Madinah Dalam Pembentukan Peradaban Multietnik Pasca Malaysia yang dirujuk serta pengetahuan sedia ada.

\section{Hasil Kajian}

\section{Tujuan Perutusan Nabi Muhammad SAW}

Al-Quran melalui ayat 107, Surah al-Anbiya' dengan jelas memaklumkan tujuan perutusan Rasulullah SAW"

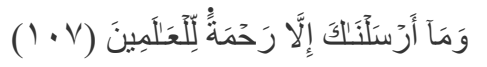

Maksud

'Dan tiadalah Kami mengutuskan engkau (wahai Muhammad), melainkan untuk menjadi kasih sayang bagi sekalian alam. (107)

Ayat ini memberi isyarat Nabi Muhammad SAW peranan kasih sayang meliputi semua makhluk, manusia, jin, haiwan, tumbuh-tumbuhan dan lain-lain. Sifat kasih sayang yang ada pada diri berupaya menjauhkan manusia berlaku zalim. Berikut antara sunnah nabi SAW yang mempamerkan sifat kasih sayang :

1) mengasihi warga tua. Satu ketika Nabi SAW melihat seorang wanita tua sedang memikul kayu api dalam cuaca panas. Setelah keletihan wanita tua itu berhenti rehat, Nabi SAW menghampiri wanita tua dan menawarkan bantuan memikul kayu api sehingga ke rumah wanita tua terbabit. Wanita berkenaan gembira dengan sifat kasih sayang Nabi SAW.

2) mengasihi musuh. Satu ketika sahabat menyarankan Nabi SAW mendoakan kejahatan dan kemusnahan kaum musyrikin yang mengganggu dakwah Nabi SAW. Baginda bersabda: "Sesungguhnya aku tidak diutuskan sebagai pembawa laknat (kepada komuniti lain) tetapi aku diutuskan sebagai pembawa kasih sayang".

(hadis sahih Muslim).

3) mengasihi kanak-kanak. Menjadi kelaziman Nabi SAW mengusap dan mengucup dahi kanak-kanak yang ditemui. Suatu ketika baginda ditegur komuniti Arab Badawi mengenai perbuatan itu. Lalu Baginda bersabda: "Sesiapa yang tidak mengasihi, nescaya dia tidak akan dikasihi".

4) mengasihi binatang. Rasulullah SAW menyampaikan mesej begitu jelas dalam hadis riwayat al-Imam al- Hakim yang bermaksud: "Sesiapa yang dengan sewenang-wenang membunuh burung atau haiwan lain yang lebih kecil daripadanya, maka Allah SWT akan meminta pertanggungjawaban kepadanya".

Perkataan kasih sayang ini perlu ditafsirkan secara hikmah dan cermat, tidak boleh terlalu bersifat 'apolegetik' dalam menterjemahkan kasih sayang sehingga menggadaikan prinsip beragama. Dalam meraikan komuniti bukan Islam, kita tidak boleh bertoleransi dalam hal yang bercanggah dengan perintah agama. Misalnya berkompromi dalam soal judi dan arak atas alasan menjaga hati. Hal ini tidak dibenarkan kerana ia bercanggah dengan prinsip Islam yang mengharamkan judi dan arak atau membolehkan kumpulan lesbian, gay, biseksual dan transgender (LGBT) berkongsi tandas dengan komuniti kurang upaya (OKU). 


\section{Jenayah Syariah terhadap LGBT}

Banyak kaedah yang boleh diambil dalam menangani dan menyantuni golongan LGBT. Golongan ini memang perlu disantuni dan ditarbiahkan supaya pulang ke pangkal jalan, golongan ini juga tidak boleh dianggap terjebak dalam kes yang dikategorikan sebagai jenayah syariah. Pendekatan undangundang perlu dalam membendung dan menyekat gejala ini agar tidak menjadi virus kepada komuniti. Hal ini disebabkan kesejahteraan sesebuah komuniti ditentukan oleh dua komponen penting, iaitu pendidikan dan undang-undang. Kedua-duanya perlu berjalan serentak. Manusia perlu dididik, dan dikawal undang-undang. Tidak semua manusia boleh dibentuk melalui bimbingan dan pendidikan. Golongan LGBT ini perlu dicegah dan dikawal dengan undang-undang supaya tidak menjadi ancaman keselamatan komuniti lain.

\section{Amalan Berkasih Sayang Bukan Konsep Baharu}

Amalan berkasih sayang bukan norma baharu. Mesej dakwah dibawa Nabi Muhammad SAW bersifat sejagat dan kasih sayang untuk seluruh alam. Sesuai dengan pengutusan baginda sebagai kasih sayang kepada sekalian alam sepertimana yang dinyatakan dalam Surah al-Anbiya', ayat 107 di atas. Ulama membincangkan secara jelas berasaskan ayat ini. Rumusan yang diambil merujuk kepada makna kasih sayang. Justeru, Islam adalah agama yang mempromosikan kasih sayang kepada semua makhluk Allah SWT dan menjadi tanggung jawab umat Islam sebagai umat terbaik untuk menterjemahkan konsep kasih sayang dalam kehidupan seharian supaya menjadi contoh kepada bukan Islam.

Tutur kata dan perilaku sebahagian komuniti Malaysia ada yang menodai konsep kasih sayang seperti isu-isu yang diutarakan dalam media Facebook. Banyak ungkapan dan tohmahan dizahirkan komuniti yang mengaku diri mereka kononnya berakhlak baik dan bermoral, tetapi menghamburkan kata-kata nista, umpat dan keji. Umat Islam adalah kelompok majoriti di Malaysia seharusnya menjadi model mempamerkan nilai-nilai kasih sayang agar menjadi dakwah bil hal (dakwah dengan contoh) kepada bangsa dan agama lain. Masih belum terlambat bagi yang terlajak dalam perlakuan dan perkataan seperti yang dinyatakan, kembali kepada asas agama supaya menjadi umat contoh menyebarkan konsep kasih sayang dalam kehidupan seharian.

\section{Piagam Madinah}

Piagam Madinah adalah suatu perlembagaan bertulis dan dipersetujui bersama oleh semua golongan komuniti Islam Madinah dan Yahudi yang menjadi warganegara Madinah yang ketika itu ditadbir urus oleh Rasulullah SAW. Disebut 'Sahifah al Madinah' kerana ia merupakan perlembagaan bertulis pertama di dunia serta menjadi asas kepada pembentukan negara Islam. Terdapat 10 Bahagian dan 47 fasal. 23 fasal berkaitan peraturan antara komuniti Islam dan 24 fasal lagi berkaitan komuniti Yahudi. Menurut Hamidullah, terdapat artikel-artikel seperti Samuel dalam Tanakh (Old Testament), ArthaSastra oleh Kauthilya serta Manusmrti dalam tradisi Hinduisme dan juga Athenaian Politea (The Constitution of The Athenians) oleh Aristotle, yang kebanyakan tulisan dalam artikel tersebut berkaitan nasihat-nasihat raja kepada putera raja dan persejarahan yang tidak menunjukkan perkaraperkara atau fasal-fasal dalam perlembagaan (Hamidullah, $1983: 5-6$ ).

Menurut kajian sejarawan, terbentuknya Piagam Madinah melalui perjanjian Aqabah pertama yang dihadiri 12 komuniti penduduk Madinah ke Makkah dan berjanji meninggalkan amalan syirik, membunuh anak, tidak menipu dan mentaati perintah Rasulullah SAW. Kemudian diikuti penerimaan komuniti Yathrib terhadap ajaran Islam. Mus'ab ibn Umar diutus ke Madinah mengajar al Quran oleh Rasulullah SAW dan sambutan yang diterima amat menggalakkan terutama daripada etnik Aus dan Khazraj. Selanjutnya diadakan ikatan perjanjian Aqabah Kedua yang melibatkan 73 komuniti lelaki dan 2 komuniti wanita Madinah, dibawa oleh Mus'ab bertemu Rasulullah SAW lalu berbai'ah untuk menjaga dan mempertahankan perjuangan dakwah Rasulullah SAW, di samping berikrar tidak sekali-kali berpecah, bercakap sombong dan taat setia sama ada ketika senang atau sukar (W.Abdullah, 1997:67). 


\section{Piagam Madinah Asas Kesepaduan dan Peradaban}

Kandungan Piagam Madinah secara jelas menekankan aspek kepimpinan yang mampu menjamin kesepaduan etnik meskipun berlainan agama dan bangsa. Antara kandungan utama Piagam Madinah meletakan baginda Rasulullah SAW sebagai Ketua Negara Madinah yang dipersetujui secara bersama dan tidak sedikit pun dibantah etnik bukan Islam. Sementara rakyat pula terdiri daripada warganegara Madinah dan sekitar Madinah sebagai asas yang meliputi etnik Islam dan etnik bukan Islam. (Norhasidah, 2001 : 13). Menyentuh perkara tentang pengiktirafan sebagai rakyat Madinah ditentukan al Quran dan al Hadith yang mana warganegara umum Madinah terdiri daripada mereka yang mematuhi perintah Allah SWT dan Undang-undang Negara atau kepada Ketua Negara sedangkan Allah SWT adalah Kemuncak yang wajar ditaati. Manakala bagi yang bakal menjadi warganegara Madinah daripada kalangan etnik bukan Islam adalah terdiri daripada etnik yang ingin hidup dalam suasana aman dan sanggup membayar jizyah (Cukai Keamanan / Keselamatan) atau dengan kata lain mereka yang bukan Islam sanggup mematuhi undang-undang perlembagaan Islam manakala etnik yang digelar sebagai 'kafir harbi' pula adalah musuh Islam dan tidak diiktiraf sebagai warganegara Madinah malah sebagai musuh yang wajib diperangi ( Abdullah Al Qari Hj.Salleh 1985 hlm : 283284).

Meskipun terdapat pelbagai cabaran dan halangan pada peringkat awal penubuhan kerajaan Islam Madinah yang warganegaranya terdiri daripada kepelbagaian etnik dan agama. Namun Rasulullah SAW sendiri tidak pernah berputus asa. Matlamat mewujudkan negara aman di bawah pentadbiran Madinah diteruskan Rasulullah SAW meskipun rakyat baginda terdiri daripada etnik berbilang kaum tetapi masing-masing mempunyai tugas dan tanggungjawab merealisasikan penubuhan negara Madinah. Sehubungan itu rakyat Malaysia perlu berasa bangga terutama kalangan etnik Islam. Jika dilihat daripada sejarah tamadun Islam, peranan ini telah lama dimainkan oleh Rasulullah SAW yang boleh bekerjasama dengan etnik berbilang kaum dan bukan sebaliknya.

Pewujudan negara'baldatun tayyibah wa rabbun ghafur' tidak akan menjadi kenyataan jika dikaitkan dengan masalah kaum atau komuniti majmuk . Begitu juga dengan impian dan hasrat Perdana Menteri Malaysia mungkin tidak akan menjadi kenyataan jika dikaitkan dengan isu perkauman. Piagam Madinah merupakan suatu kontrak sosial yang menjamin keselamatan kepada semua warga Madinah merangkumi umat Islam dan bukan Islam. Keselamatan yang dimaksudkan adalah akal, maruah, harta, nyawa dan agama. Turut ditekankan adalah konsep kerjasama dan jalinan harmoni antara pelbagai etnik, bahasa, keturunan, agama dan warna kulit. Fenomena ini menunjukkan kemahiran Rasulullah SAW dalam mentadbir negara, memberi hak-hak kewarganegaraan tanpa mengira warna kulit, latar belakang kehidupan dan budaya selaras dengan kandungan 10 Bahagian Piagam Madinah. Perkara yang sama ditekankan dalam pembinaan negara Malaysia yang menekankan aspek maqasid syariah meliputi penjagaan agama, nyawa, akal, keturunan dan harta sama ada dalam kehakiman dan perundangan, dakwah dan media, pendidikan dan modal insan, masjid, penyelidikan dan maqasid serta sosio-ekonomi.

Antara Intipati besar 10 Kandungan Piagam Madinah yang boleh dijadikan rujukan dalam era PascaMalaysia dan terbukti berjaya menyatupadukan warga Madinah yang multietnik ke arah kebaikan, keamanan dan keselamatan. Secara tidak langsung membentuk sebuah ummah yang mentaati kepimpinan Rasulullah SAW dalam satu acuan pemerintahan yang diterima ramai.

i. Mengakui Nabi SAW, ketua negara Madinah

ii. Mengakui Ansar dan Muhajirin sebagai umat yang bertanggungjawab terhadap agama, rasul dan komuniti Islam

iii. Setiap kaum bebas beragama dan mengamalkan cara hidup masing-masing

iv. Komuniti Islam dan Yahudi bertanggungjawab terhadap keselamatan negara daripada serangan musuh

v. Komuniti Yahudi dibenarkan hidup dengan cara mereka serta menghormati komuniti Islam tetapi tidak dibenarkan melindungi komuniti kafir musyrikin Quraisy

vi. Setiap komuniti bertanggungjawab menjaga keselamatan dan mengekalkan perpaduan di Madinah 
DOI: https://doi.org/10.47405/mjssh.v6i8.922

vii. Setiap individu tidak boleh menyakiti dan memusuhi individu atau kaum lain. Hendaklah tolong menolong demi pembangunan ekonomi, dan keselamatan

viii. Setiap kaum perlu merujuk Rasulullah SAW (ketua negara) jika berlaku perbalahan

ix. Mana-mana pihak dilarang berhubungan dengan pihak luar terutama Musyrikin Mekah dan sekutu mereka

x. Piagam ini mempunyai kuasa melindungi pihak yang mempersetujuinya dan hak mengambil tindakan pada sesiapa yang melanggarnya

Seperti yang dinyatakan dalam Bahagian 6 di atas jelas menjelaskan aspek perpaduan yang wajar dipraktikkan oleh semua kaum bagi tujuan penyatuan dan perpaduan etnik dan mengelak sakit menyakiti atau mencaci etnik lain. Dengan kepelbagaian etnik di Madinah seperti Aus, Khazraj, Auf, Sa'idah, Jusham, al Najjar, al Harith, Tha'labah, Jafnah, Shutaybah, Nadir, Qainuqa', bani Qurayzah dan lain-lain agama seperti Islam, Yahudi, Kristian dan animisme (pagan) dan kumpulan kecil lain tetapi baginda Rasulullah SAW berjaya menyatupadukan mereka di bawah perlembagaan Piagam Madinah (Yusri, 2009 : 6). Manakala dalam teras negara 'baldatun tayyibah warabbun ghafur' pula menekankan aspek-aspek berikut :

1. Islam sebagai kasih sayang bagi sekalian alam, membawa keamanan, kemakmuran dalam komuniti

2. Pentadbiran berasaskan maqasid syariah yang menekan aspek penjagaan agama, nyawa, akal, keturunan dan harta

3. Tampil dengan model Malaysia yang sesuai dengan keadaan (waqi'), adat dan budaya bangsa Malaysia tanpa meninggal asas-asas Islam

\section{Kesan Pembentukan Piagam Madinah dalam Penyatuan dan Perpaduan Multietnik}

Kesan yang paling nyata dapat dilihat adalah dalam aspek politik dengan tertubuhnya negara Islam pertama di dunia. Sementara warga Madinah bukan Islam mengiktiraf kepemimpinan Islam Madinah yang menunjukkan tidak ada sikap prejudis terhadap kepimpinan negara Islam. Malahan diakui etnik bukan Islam, mereka berasa lebih selamat berada di bawah pemerintahan negara Islam yang mengamalkan corak pemerintahan adil, amanah, toleransi, bekerjasama dengan pelbagai etnik Islam dan bukan Islam, hormat menghormati meskipun dalam spektrum berlainan pegangan dan praktis ziarah menziarahi pada musim perayaan, musibah atau lain-lain situasi. Malahan Nabi SAW memandang berat terhadap mereka yang menyakiti kafir zimmi. Rasulullah SAW bersabda: "Sesiapa menzalimi kafir yang diikat perjanjian setia kepada kerajaan Islam atau mengurangkan haknya, atau membebankannya di luar keupayaannya atau diambil sedikit daripada haknya tanpa kebenarannya, maka aku menjadi pembelanya pada hari Kiamat." (Riwayat Abu Dawud)

Dalam aspek pentadbiran, majoriti warga Madinah mengundi dan sebulat suara menerima kepimpinan Rasulullah SAW sebagai Ketua Negara Islam. Perubahan dalam pentadbiran Rasulullah SAW yang mempamerkan anjakan paradigma terutama dalam memasyarakatkan warga Madinah dengan kaedah penempatan tersusun antara jiran multietnik serta mewujudkan hubungan diplomatik dengan negara luar. Islam adalah agama perdamaian dan agama toleransi. Ia bukan kata-kata kosong tetapi dijelaskan Allah SWT dalam al-Quran dan dibuktikan secara praktikal oleh Rasulullah SAW melalui sejarah kehidupan serta perjuangan Baginda. Perkara pertama dilakukan Rasulullah SAW setiba di Madinah ialah mengadakan perjanjian dengan Yahudi. Antara intipati perjanjian, negara Islam Madinah menghormati kepercayaan mereka, mempertahankan dari segala bentuk ancaman dan menjadikan mereka masyarakat Madinah yang akan mempertahankan setiap inci buminya

Kesan yang memberangsangkan juga adalah dalam sektor ekonomi. Ia semakin maju dalam bidang penternakan, agrobio, pertanian, perdagangan dan perusahaan. Warga Madinah yang multietnik dan agama dapat mengurus perniagaan, pemasaran dan menghasilkan produktiviti yang baik antara satu sama lain, impak hubungan harmonis antara kaum. Kemenangan besar diperoleh dalam banyak 
peperangan melipatgandakan lagi jumlah simpanan perbendaharaan atau Baitul Mal yang juga digunakan untuk perbelanjaan negara dan kebajikan rakyat. Rasulullah SAW mengutamakan sistem ekonomi berasaskan al-Qur'an yang menekankan keadilan. Untuk menjamin keadilan dan memastikan agar kekayaan tidak dibolot oleh segolongan kecil ahli masyarakat sahaja, maka pelbagai institusi ekonomi ditubuhkan seperti institusi zakat, sedekah, baitul mal, waqaf, pusaka, kharaj dan lain-lain. Melalui institusi-institusi ini, hak orang kaya dijamin keselamatannya, manakala orang miskin pula dibela dan dibantu dengan sewajarnya. Sistem ekonomi Rasulullah s.a.w. menghapuskan amalan riba yang dipraktikkan orang Yahudi Madinah kepada orang Arab. Masyarakat Islam dikenakan zakat, bagi yang bukan Islam perlu membayar kharaj dan jizyah. Ia menunjukkan wujud kebersamaan dan tanggungjawab terhadap negara. Kharaj bermaksud cukai hasil tanah yang dikenakan ke atas orang bukan Islam. Dalam undang-undang syariah, Kharaj ialah cukai ke atas tanah pertanian.

Abu Ubaid meriwayatkan dalam kitab Al-Amwal dari Az-Zuhri yang mengatakan : " Rasulullah s.a.w menerima jizyah daripada orang Majusi Bahrain." Tambah Az-Zuhri lagi: "Siapa sahaja dalam kalangan mereka yang memeluk Islam, maka keIslamannya diterima, dan keselamatan diri dan hartanya akan dilindungi melainkan tanah. Kerana tanah adalah tanah fai' (rampasan) bagi kaum Muslimin, kerana orang itu tidak menyerah diri sejak awal, sehinggalah dia dilindungi." ( dilindungi oleh kaum Muslimin).

Kesan yang terserlah dalam bidang sosial yang mana aspek perpaduan menonjol sekali di bawah pakatan perjanjian Piagam Madinah, semangat jahiliah dihapuskan, diganti dengan semangat patriotik mempertahankan negara yang akhirnya melahirkan negara Madinah yang harmoni, aman, tiada percanggahan politik, sentimen perkauman. Semua rakyat mendapat hak yang sama, bebas mengamalkan agama, mengekalkan budaya, adat resam dan bahasa ibunda. Pada pandangan penulis, pembentukan Piagam Madinah mendatangkan manfaat kepada warganegara Madinah lantaran ada beberapa peruntukan yang termaktub dalam Piagam Madinah. Peruntukan tersebut berkaitan dengan hak warganegara dan hak bukan warganegara Madinah. Antara peruntukan yang dimaksudkan untuk hak warganegara seperti :

1. Peruntukan berkaitan hak dan tanggungjawab etnik Islam seperti fasal 3 hingga 12 , $13,17,18,19,20,21,22$ dan 23

2. Peruntukan berkaitan hak dan tanggungjawab etnik bukan Islam seperti fasal 16 , $24,25,26,27,28,29,30,31,32,33,34,35$ dan 37

3. Peruntukan berkaitan hak dan tanggungjawab antara etnik Islam dan etnik bukan Islam seperti fasal 15, 22, 36, 37, 39, 40, 41, 42, 43, 44, 45 dan 47.

Sementara peruntukan yang bukan warganegara seperti :

1. Peruntukan berkaitan hak dan tanggungjawab bukan warganegara yang datang ke Madinah termaktub dalam fasal 47

2. Peruntukan berkaitan hak dan tanggungjawab etnik Islam dan etnik bukan Islam pula, khasnya etnik Yahudi seperti fasal 3, 4, 5, 6, 7, 8, 9, 10, 11, 12 dan fasal 25, $26,27,28,29,30,31,32,33,34$ dan 35

\section{Unsur-Unsur Positif Kewujudan Piagam Madinah}

Jika dilihat secara umum, terdapat banyak unsur-unsur positif yang boleh dipraktikkan di Malaysia dengan mengambil kira kepentingan unsur-unsur positif yang termaktub dalam perlembagaan Madinah. Kepentingan maqasid syariah perlu diterapkan dalam komuniti Malaysia yang berbilang agama, ras dan budaya dan boleh disesuaikan dengan isi kandungan Piagam Madinah. Dari aspek individu, Piagam Madinah mampu melahirkan rasa hormat dan hubungan silaturahim yang kukuh tanpa mengira etnik Islam dan etnik bukan Islam, manakala komuniti pula dapat hidup dalam keadaan harmoni, aman damai dan dapat meringankan beban kerja melalui semangat kerjasama dan pada masa yang sama juga Malaysia akan berupaya bangkit maju dan membangun dengan pesat serta dihormati 
komuniti antarabangsa. Setiap individu dan warganegara pula dijamin dengan peruntukan-peruntukan yang telah dijelaskan di atas termasuk dalam aspek perlaksanaan syariat, menjadikan Islam sebagai cara hidup dan boleh diamalkan oleh sesiapa sahaja. Perkara yang paling utama juga, gerakan dakwah dapat diselaraskan dengan baik oleh agensi-agensi dakwah dalam sebuah negara yang aman seperti Malaysia. Di samping memelihara keamanan dan keharmonian kaum.

\section{Nilai Toleransi Dalam Peradaban Multietnik}

Penghormatan terhadap etnik bukan Islam juga telah dibuktikan Rasulullah SAW di awal pembentukan Piagam Madinah. Baginda secara jelas menyatakan komuniti Yahudi sebagai satu umat. Antara butiran kesepakatan yang tertera dalam Piagam Madinah adalah sesiapa yang hidup dan tinggal di wilayah Madinah, sama ada etnik Islam dan bukan Islam selagi tidak berbuat zalim (makar), mereka wajar mendapat hak perlindungan dan keamanan. Perkara ini dinyatakan juga dalam hadith yang diriwayatkan oleh Abu Daud yang bermaksud :

'Sesiapa menyakiti komuniti bukan Islam yang berada di bawah perlindungan Islam, maka dia telah menyakiti saya, dan sesiapa yang menyakiti saya, maka dia telah menyakiti Tuhan,

Riwayat Abu Daud

Hal yang sama juga dalam aspek menghormati agama penganut lain selain Islam. Sebarang tindakan kekerasan terhadap etnik bukan Islam dengan alasan berbeza agama tidak sama sekali dibenarkan syariat. Meskipun terdapat hadis yang membicarakan etnik Yahudi dan Nasrani tidak akan menerima Islam dan berterusan membenci umat Islam seperti yang berlaku di Palestin, Bosnia Herzegovina, Iraq, Myammar, Xinxiang, China, Afghanistan dan negara-negara Islam lain, namun kita sebagai umat Islam lebih-lebih lagi di Malaysia yang mempunyai komuniti majmuk dan pelbagai agama tidak dibenarkan memusuhi dan memerangi tanpa alasan.

Malahan Islam mengajar bagaimana cara menghormati dan melindungi hak penganut agama lain, bersikap adil terhadap mereka yang berbeza akidah dengan syarat hak Islam tidak digugat sepertimana yang dirakam dalam surah al Mumthanah ayat 8-9 yang bermaksud :

\section{Allah SWT tidak melarang kamu daripada berbuat baik dan berlaku adil kepada komuniti yang tidak memerangi kamu kerana agamamu, dan tidak mengeluarkan kamu dari kampung halaman kamu. Sesungguhnya Allah SWT mengasihi komuniti yang berlaku adil ${ }^{2}$}

Sehubungan itu juga, Islam juga telah mengatur prinsip-prinsip dan dasar dalam semua kehidupan umat manusia termasuk konsep toleransi dan cara hidup dengan komuniti yang terdiri daripada berbagai macam suku bangsa, ras, agama dan etnik. Malahan kita turut dilarang mencemuh dan mencaci agama lain demi perpaduan antara umat manusia seperti yang dijelaskan dalam firman Allah SWT dalam surah al An'am ayat 108 yang bermaksud :

\section{'Dan janganlah kamu mencaci sesuatu yang mereka sembah selain daripada Allah SWT, kerana mereka kelak akan mencaci Allah SWT secara berlebihan tanpa pengetahuan..."3}

Sekiranya diperhatikan apa yang berlaku di Malaysia terdapat unsur-unsur kesepaduan yang ditekankan menerusi Perlembagaan Malaysia bagi menjamin perpaduan antara kaum. Terdapat pelbagai usaha yang dijalankan oleh pimpinan negara selepas kemerdekaan untuk mengekalkan

\footnotetext{
${ }^{1}$ Hadith Riwayat Abu Daud

${ }^{2}$ Surah al Mumthanah : 8-9

${ }^{3}$ Surah al An'am : 108
} 
perpaduan agar peristiwa rusuhan kaum seperti 13 Mei 1969 (Abdullah Jusoh, 1989 : 82) dan peristiwa Kg. Medan 4-8 Mac 2001 tidak berlaku lagi. Dengan slogan 'Negara Rahmah' ia merupakan langkah tepat yang diambil ke arah kesepaduan kaum di Malaysia dan meneruskan usaha pimpinan negara terdahulu bermula dengan Tengku Abd. Rahman, Tun Hussein Onn, Tun Abd. Razak, Tun Abdullah Hj. Ahmad Badawi dan Dato' Mohd Najib Abd Razak dan kini Perdana Menteri Tun Dr. Mahathir Mohamad.

Berikutan peristiwa tersebut banyak langkah yang telah diambil pihak kerajaan Malaysia bagi memastikan keharmonian etnik di Malaysia terpelihara hingga pada akhirnya berlakunya akomodasi dan asimilasi kaum (Shamsul Amri, 2008 : 170-185). Antaranya adalah seperti:

- Memperkenalkan konsep setinggan sifar (Rahmah Hj. Ab.Kassim 2003 :8)

- Penubuhan Jabatan Perpaduan Negara dan Integrasi Nasional

- Dasar Bahasa Kebangsaan

- Dasar Kebudayaan Kebangsaan

- Kebebasan Beragama seperti yang termaktub dalam Perlembagaan dan Rukun Negara

- Memperkasakan Sekolah Kebangsaan dan Sekolah Wawasan

- Program Latihan Khidmat Negara (2004)

Hasil daripada dasar yang diperkenalkan di atas telah diterjemahkan oleh etnik berbilang kaum dalam bentuk mengadakan rumah terbuka setiap kali tiba musim perayaan berlainan etnik, penerimaan budaya lain seperti dalam aspek pemakanan dan pakaian etnik lain dan juga program-program yang dijalankan di IPTA atau IPTS melalui persatuan dan kelab yang diwakili oleh pelbagai etnik memegang jawatan tertinggi.

\section{Kesimpulan}

Dalam suasana komuniti multietnik di Malaysia perlu diberi perhatian dan memahami kehendak di sebalik penerapan Sahifah Madinah. Kemajmukan komuniti Malaysia dengan kepelbagaian bangsa, etnik, ras, agama, adat, bahasa dan kepercayaan haruslah menjadi pertimbangan dalam menggariskan kaedah dan cara penerapan tersebut Walaupun demikian bukan bererti kita perlu merubah atau mengurangi konsep dan prinsip yang menjadi teras kepada perpaduan nasional. Adalah menjadi situasi yang keliru apabila sebahagian komuniti Malaysia di negara kita yang menganggap faktor kemajmukan penduduk negara ini merupakan penghalang perlaksanaan kesepaduan etnik sepenuhnya. Sikap seperti ini seolah-olah menafikan tentang keadilan, kesaksamaan, rasa kekitaan, kedudukan sesebuah komuniti dan negara di semua peringkat warganegara Islam atau warganegara bukan Islam sepertimana yang dianjurkan Islam agar saling hormat menghormati antara satu sama lain meskipun berbeza keyakinan. Pada hakikatnya negara Islam Madinah yang diasaskan Rasulullah SAW sewajarnya dijadikan model terbaik bagaimana sistem Islam dan perlembagaan Piagam Madinah dapat diterima dan dipraktikkan dalam komuniti majmuk Madinah. Faktor asas dalam perlaksanaan pentadbiran dan pembentukan komuniti sejahtera di negara kita yang perlu dibincangkan bukan dalam masalah prinsip tetapi ialah bagaimana prinsip itu dipraktikkan dan dilaksanakan. Umat Islam perlu mengambil langkah berhati-hati supaya perlaksanaan ini mengikut acuan Piagam Madinah sekurangkurangnya agar maksud yang baik tidak disalahtafsirkan oleh komuniti lain. Kita harus berusaha agar tidak terperangkap dengan keghairahan yang kita dukung dan perjuangkan.. Justeru, gagasan 'Negara Baik' yang bersandarkan kepada nilai universal dalam agenda pentadbiran negara perlu diberi penjelasan dengan sebaiknya terutama kepada warganegara Islam dalam bentuk fakta ilmiah dan akademik yang berhubung kait dengan isu-isu Islam seperti status agama Islam dalam perlembagaan, hak dan peruntukan kerakyatan dan warganegara Islam dan bukan Islam. Dalam komuniti Malaysia yang bersifat multietnik ini, apa yang perlu kita tingkatkan untuk mencapai tujuan ini ialah melalui jalan kesepaduan antara kaum. Kita harus memperhebatkan kesepaduan dalam kalangan umat Islam dan bukan Islam ini sebagai gagasan yang lengkap dan universal. Pada masa yang sama, keyakinan umat Islam terhadap peranan Piagam Madinah sebagai model harus disemai dan dipupuk dengan sebaik-baiknya. Sementara kepada komuniti bukan Islam pula, perlulah disebarkan pengertian sebenar terhadap gagasan Sahifah Madinah yang sifatnya berlaku adil kepada semua lapisan komuniti. 
Penerangan-penerangan yang jelas dengan kaedah terbaik dan praktikal pasti memberi kesan mendalam dalam kalangan komuniti bukan Islam sepertimana titah perkenan Seri Paduka Baginda Yang Di-Pertuan Agong dalam Perasmian Sidang Dewan Rakyat Oleh Seri Paduka Baginda Yang DiPertuan Agong, 11 ,Mac 2019. "Islam cara hidup universal dan membawa kasih sayang sekalian alam. Beta amat menyokong usaha kerajaan mempromosikan nilai dan budaya Islam melalui pendekatan 'kasih sayang' dan 'Maqasid syariah'. Apa yang penting kepada ialah tidak seharusnya kita berpuas hati dengan apa yang sudah kita peroleh, tetapi kita harus berusaha lagi gigih, supaya memperolehi tahap prestasi dan kualiti yang tinggi terutama dalam hubungan dengan komuniti berbilang kaum. Perkara-perkara yang menjadi ikatan kontrak sosial antara kaum Melayu, Cina dan India di Malaysia perlu dipertahankan dalam hal-hal yang berkaitan dengan kedaulatan Raja-raja Melayu, kedudukan istimewa Melayu, hak kerakyatan berasaskan prinsip jus soli dan Islam sebagai agama Persekutuan tetapi agama-agama lain boleh diamalkan (Sheikh Ghazali, 1999:13). Mungkin dari sudut sebagai rakyat Malaysia tidak akan muncul masalah untuk diterima oleh semua etnik yang terdapat di negara kita tetapi bagaimana pula dengan agama, budaya dan cara hidup yang sudah semestinya berbeza dan agak sukar untuk diselaraskan. Dalam aspek bahasa Melayu sebagai bahasa komunikasi juga tidak akan wujud masalah untuk diucapkan oleh etnik lain sebagai bahasa rasmi negara tetapi bagaimana dengan persoalan yang diajukan di atas (Jayum, 2009). Menurut Faisal (1997) Malaysia akan tetap kekal sebagai sebuah negara di bawah kepimpinan Melayu Islam dengan kerjasama golongan bukan Islam. Dengan penerapan nilai-nilai murni Islam dalam pentadbiran negara akan dapat menjamin keharmonian hidup rakyat dan meningkatkan lagi prestasi hubungan etnik antara komuniti berbilang kaum kerana sistem ini diasaskan kepada pentafsiran Islam yang murni dan bersifat dinamik lagi progresif (Faisal, 1997:126).

\section{Rujukan}

Abdul Halim Hj.Mat Diah (1989). Beberapa Masalah Ummah. Kuala Lumpur. Angkatan Belia Islam Malaysia.

Abdullah Al Qari Hj.Salleh. (1985). Muhamad Rasulullah SAW Makhluk Pilihan dan Rasul Contoh. Kelantan. Pustaka Aman Press Sdn.Bhd.

Abdullah Jusoh. (1989). Pengenalan Tamadun Islam Di Malaysia. Kuala Lumpur. Dewan Bahasa dan Pustaka

Agenda Pentadbiran Islam Malaysia Baharu. Terbitan Media Menteri. Jabatan Perdana Menteri (Agama) Kompleks Islam Putrajaya

Ahmad Nasir Mohd Yusoff (2009). 1 Malaysia Sebagai Wahana Perpaduan Dan Persaudaraan Multietnik : Rujukan Kepada Intisari Dalam Piagam Madinah. Kertas Kerja Seminar Bengkel 1 Malaysia Peringkat Negara Sempena Mesyuarat Majlis Hal Ehwal Islam Institut Pengajian Tinggi (MAHEIS) Malaysia. Anjuran Pusat Islam UPM. 24 Oktober

Ahmad Nasir Mohd Yusoff. (2020). Tamadun Islam Dan Tamadun Asia (TITAS) Membina Peradaban Di Malaysia. Penerbit Aras Mega Sdn Bhd, Kajang, Selangor.

Ahmad Nasir Mohd Yusoff. (2019). Isu-Isu Kontemporari Muslim Di Malaysia. Penerbit Aras Mega Sdn Bhd, Kajang, Selangor.

Ahmad Nasir Mohd Yusoff. et.al. (2019). Hubungan Etnik Perintis Kesepaduan Kaum. Penerbit Aras Mega Sdn Bhd, Kajang, Selangor.

Ahmad Shalaby. (1976). Masyarakat Islam. Singapura: Pustaka Nasional.

Al Quran

Al-Būṭī, Muḥammad Sa īd Ramaḍan. (1999). Fiqh al-Sīrah al-Nabawiyyah. Al-Qāhirah: Dār al-Salām

Al-Mubārakfūrī, Șafī al-Raḥmān. (2011). Al-Raḥīq al-Makhtūm. Kuala Lumpur:Yayasan Dakwah Islam Malaysia

Anthony Punan \& Aziz Deraman. (2009). Sarawak Tumpuan Pembangunan. Mingguan Sarawak. 11 Oktober (Ahad)

Bernama. (2009) Rakyat Pelbagai Kaum Sambut 1 Malaysia Utusan Sarawak 10 Oktober.

Faisal Hj.Othman. (1997). Kertas Kerja Islam dan Pembentukan Negara Malaysia Moden dalam Kecemerlangan Tamadun Islam Dalam Menghadapi Cabaran Abad Ke-15 Hijrah. Shah Alam. Terbitan Biroteks ITM. 
Fuziah Shaffie \& Ruslan Zainuddin. (2000). Sejarah Malaysia. Kuala Lumpur. Fajar Bakti Sdn.Bhd.

Hamidullah Muhammad. (1983). The First Written Constitution In The World. Hydrebad :Habib \& Co.

Hilmy Bakar Almascaty. (1994). Ummah Melayu Kuasa baru Dunia Abad Ke-21. Kuala Lumpur. Berita Publishing Sdn.Bhd.

Jayum Jawan. (2009). Kenegaraan Malaysia. Pendidikan Jarak Jauh. Selangor. Penerbit UPM Serdang.

K.Ramanathan. (1992). Asas Sains Politik. Kuala Lumpur. Penerbit Fajar Bakti

Lee Lam Thye. (1997). Mewujudkan Bangsa Malaysia. Dewan Budaya. September

Luqman Rico Khashogi, S.H.I., M.S.I. (2012). Konsep Ummah di Piagam Madinah. Jurnal Agama dan Hak Azazi Manusia, 2 (1), 93-116

Mahathir Mohamad. (1991). Wawasan 2020. Persidangan Pertama Majlis Perdagangan Malaysia Di Kuala Lumpur. 28 Februari

Mohamad Suffian Bin Hashim (1984). Mengenal Perlembagaan Malaysia. Kuala Lumpur. Dewan Bahasa dan Pustaka.

Mohd Nor Mamat (1999). Pemikiran Islam Dan Dunia Hari Ini. Selangor Univision Press Sdn. Bhd

Mohd Nazmi Mohd Khalli, Suraya Sintang \& Syamsul Azizul Marinsah (2020). Rahmatan Lil 'Alamin: Kerangka Konsep Keharmonian Di Malaysia. Jurnal Sains Insani, 5, 33-40

Muhammad Haji Muhd Taib. (1996). Melayu Baru. Petaling Jaya. Visage Communication.

Nik Mustafa Nik Hassan (1994). Nilai Sejagat Islam : Satu Perspektif. Kuala Lumpur. Institut Kefahaman Islam Malaysia

Norhasidah A. Bakar (2001) Perjuangan Rasulullah SAW . Kertas Kerja Bengkel Pengajaran Kursus Pendidikan Islam Semester (01) \& (02). Anjuran Bersama Pusat Pendidikan Islam Dan Pusat Sumber Pengajaran Dan Pembelajaran UiTM Shah Alam Selangor. 13-14 Jun.

R.S.Mine \& Diane K.Mauzy (1982). Politik dan Kerajaan Malaysia. Kuala Lumpur. Dewan Bahasa dan Pustaka.

Rahmah Hj. Ab.Kassim (2003) Ekonomi Malaysia:22 Tahun Di Bawah Kepimpinan Dato'seri.Dr.Mahathir Mohamad Perdana Menteri Malaysia. Santubong Kuching Resort. 18 Oktober

Ridhuan Tee Abdullah (2009) Peranan Pemimpin Muda. Kertas Kerja Seminar Bengkel 1 Malaysia Peringkat Negara Sempena Mesyuarat Majlis Hal Ehwal Islam Institut Pengajian Tinggi (MAHEIS) Malaysia. Anjuran Pusat Islam UPM. 24 Oktober

Risalah Sambutan Ma'al Hijrah 1414 H. (1993). Peringkat Negeri Sarawak. Dewan Suarah Bintulu 21 Jun.

Shamsul Amri Baharuddin (2008). Modul Hubungan Etnik. Shah Alam. Selangor . UPENA. UiTM

Sheikh Ghazali Bin Hj.Abd.Rahman. (1999). Kedudukan dan Bidangkuasa Mahkamah Syariah:Perkembangan Terkini dalam Syarahan Memoir dan Perlancaran Buku Undang-undang Keluarga Islam Di Malaysia. Anjuran Unit Pendidikan Islam, UiTM Shah Alam, Selangor. Terbitan Malayan Law Journal Sdn.Bhd. 9 Oktober

W. Abdullah W.Mahmood. (1997). Tamadun Islam dan Tamadun Alam Melayu Serta Sumbangannya Kepada Dunia. Selangor. Global Printer Sdn.Bhd. c.1

Wan Mohd Zahid Mohd Nordin. (1993). Wawasan Pendidikan Agenda Pengisian. Kuala Lumpur. Nurin Enterprise

Yusri Mohamad Ramli. (2009). Kertas Kerja Gagasan Satu Malaysia Dalam Spektrum Kemajmukan Warga: Satu Analisa Berdasarkan Perspekktif Islam Dengan Rujukan Khusus Kepada Klausa Satu Ummah Dalam Sahifah Madinah dalam Prosiding Pemikiran Islam Peringkat Antarabangsa. 6-7 Oktober

Zulkefli Aini (2009) Potensi Untuk Mencapai Konsep Kasih sayang tersebut Kertas Kerja Seminar Bengkel 1 Malaysia Peringkat Negara Sempena Mesyuarat Majlis Hal Ehwal Islam Institut Pengajian Tinggi (MAHEIS) Malaysia. Anjuran Pusat Islam UPM. 24 Oktober

Zulkifli Mohamad. et.al (2006). Tamadun Islam \& Tamadun Asia (TITAS). Pusat Pengajian Umum. Universiti Kebangsaan Malaysia. Bangi Selangor 